\title{
The RAE-ification of Tourism Research in the UK
}

John Tribe

Buckinghamshire Chilterns University College, High Wycombe, Bucks HPII 2JZ, UK

\begin{abstract}
Whereas those working on the inside of tourism generally feel that tourism research is making good progress, the 2001 Research Assessment Exercise (RAE) in the UK offered an outsiders' assessment of UK tourism research that was less benign. This paper examinesthe results and consequences of the RAE based on an examination of the submissions made by UK higher education institutions. It describes the position of tourism in the RAE and focuses on three key issues-structure, outcomes and visibility. It invokes Kuhnian and Foucauldian perspectives to foreground hidden consequences of the RAE (termed RAE- ification by the author) that threaten the development of UK tourism research. The article concludes that tourism research, finding itself on the periphery of UK research, faces similar problems to those faced by peripheral tourism regions.
\end{abstract}

Keywords: research; RAE; structure; discourse; visibility; peripherality.

\section{INTRODUCTION}

From the cosy world of the inside, tourism research seems to be developing quite nicely. It seems to be expanding. There are in excess of 37 journals, which publish more than 500 research articles each year. The journals are often international in character and insiders tend to rate Annals of Tourism Research and Tourism Management quite highly. Tourism has established a circuit of national and international conferences where delegates politely applaud each other's new (and some- times recycled) findings, conduct coherent discussions and slightly less coherent ones in the bars, pubs and clubs. In short tourism has aped and assembled much of the academic rites, rituals and relics of the more established disciplines. Of course there exist different camps and conflicts within the community of tourism scholars and researchers. Imagine a conversation between Keith Hollinshead (sociology) and John Swarbrooke (marketing): 'Don't you tell me Foucault, Keith'. There are distinct subtribal (Becher, 1989) languages: those who talk about the gaze, the other, authenticity and discourse $f$ ind it difficult to talk with those who discuss tourism in terms of yield management, multipliers, service quality and distribution channels. Tourism has chairs, PhD students and even the odd prima donna. In fact everything in tourism research was going well until-in the UK at leastthe RAE (Research Assessment Exercise) in 2001.

The UK in the twenty first century has become obsessed by measurement, performance and deliverables at the organisational and individual level. In the public sector, police have targets for crime (perhaps a bit of an irony here) and hospitals have targets for waiting lists. The railways too have targets but despite these Railtrack has become the international byword for poor service quality. Individual workers are set targets arising from annual appraisal. Hapless academics have not escaped the surveillance of the State, which uses the RAE to monitor research quality. The 2001 RAE measured the quality of submitted university research in the UK between 1996 and 
2001. Each submission was awarded a mark on a scale of $1-7\left(1,2,3 b, 3 a, 4,5,5^{\star}\right)$. The meanings of this scale are described in Table 1. 'The main purpose of the Research Assessment Exercise (RAE) is to enable the higher education funding bodies to distribute public funds for research selectively on the basis of quality.' (http://www.hero.ac.uk/rae/AboutUs/). In the RAE, Universities make a submission that includes details of research grants obtained, PhD students, an account of research, indicators of esteem and a list of four research outputs attributable to each of the researchers they wish to include (RAE Team,1999b).

Insiders all know the importance of tourism including its contribution to GNP, employment and balance of payments and its regenerative powers to depressed regions and stressed humans. Tourism has even found a recent place in some structures and practices in UK higher education. It was clearly identified in the recent QAA (Quality Assurance Agency) subject review of quality in subject area 25. Its higher education programmes have been specified under the QAA benchmarking exercise and it has a prominent place in the Learning and Teaching Subject Network (LTSN) under Centre 22. So how did tourism do in the RAE? The blunt answer is very badly indeed. This paper will examine the results and consequences of the RAE based on a critical examination of the submissions made by UK higher education institutions and the evaluations of research and reports on sub- mission made by the RAE team. It describes the position of tourism in the RAE and focuses on three key issues-structure, outcomes and visibility. It will use Kuhnian and Foucauldian perspectives to foreground hidden consequences of the RAE that threaten the development of UK tourism research. Kuhn is deployed to emphasise both the conservative influences at work in academic research and progress and the dificulties that the new has in emerging in a world dominated by the old. Foucault is used to demonstrate the under- lying influences of power that influence knowledgeproduction.

\section{METHOD OF DATA COLLECTION}

The data used for this enquiry came from two main sources. The first was the overview reports from the RAE panels (RAE Team, 2002). The second was the document published by the RAE team that included all the submissions made by Institutions of Higher Education across all 69 panels or Units of Assessment (UoA). This is available online as a searchable data base (www.rae.ac.uk). This data base was interrogated in a number of different ways. First it was searched for the

Table 1. The Research Assessments Exercise rating scale (Source: RAE Team, 1999b)

\begin{tabular}{ll}
\hline Rating & \multicolumn{1}{c}{ Explanation } \\
\hline $5^{*}$ & $\begin{array}{l}\text { Quality that equates to attainable levels of international excellence in more than half of the } \\
\text { research activity submitted and attainable levels of national excellence in the remainder } \\
\text { Quality that equates to attainable levels of international excellence in up to half of the research } \\
\text { activity submitted and to attainable levels of national excellence in virtually of all the remainder }\end{array}$ \\
3 & $\begin{array}{l}\text { Quality that equates to attainable levels of national excellence in virtually all of the research } \\
\text { activity submitted, showing some evidence of international excellence }\end{array}$ \\
$3 \mathrm{Q}$ & $\begin{array}{l}\text { Quality that equates to attainable levels of national excellence in over two-thirds of the research } \\
\text { activity submitted, possibly showing evidence of international excellence }\end{array}$ \\
2 & $\begin{array}{l}\text { Quality that equates to attainable levels of national excellence in more than half of the research } \\
\text { activity submitted } \\
\text { Quality that equates to attainable levels of national excellence in upto half of the research activity } \\
\text { submitted } \\
\text { Quality that equates to attainable levels of national excellence in none, or virtually none, of the } \\
\text { research activity submitted }\end{array}$ \\
\hline
\end{tabular}


Table 2. Examples of larger research groups

\begin{tabular}{lcccc}
\hline Institution & $\begin{array}{c}\text { Unit of } \\
\text { Assessment }\end{array}$ & Rating & $\begin{array}{c}\text { Number of tourism } \\
\text { researchers submitted }\end{array}$ & $\begin{array}{c}\text { Total number of } \\
\text { tourism } \text { articles }^{\text {a }}\end{array}$ \\
\hline Surrey & 43 & 4 & 13 & 44 \\
Luton & 43 & 4 & 11 & 22 \\
Strathclyde & 43 & 4 & 6 & 22 \\
Shefield/Sh. Hallam & 69 & 4 & 8 & 21 \\
North London & 43 & $3 a$ & 12 & 47 \\
Bournemouth & 43 & $3 a$ & 7 & 26 \\
Derby & 43 & 2 & 8 & 22 \\
\hline
\end{tabular}

a In some cases articles have been removed from published data for reasons of confidentiality. Also some 'new' researchers submitted less than four outputs.

term 'tour' (to include the terms tourism and tourist). This yielded an output of multiple occurrences. From this a list was compiled that showed all the UoA submissions that had this term in at least one of their recorded research outputs (see Table 4 for a summary of this list). Second, a sample of larger and smaller tourism submissions was made. The list was compiled from the researcher's own knowledge. From this list a detailed search was made of all the outputs (and their authors) containing the search string 'tour*'. Tables 2 and 3 summarise the findings of this analysis. Third, all $5^{\star}$ rated submissions that included an output that contained the search string 'tour' were identified and analysed.

There is of course an important caveat that is attached to this method. The search string 'tour' does not provide a list of outputs that have a complete correspondence with actual tourism research outputs. On the one hand it provides an underestimate by not identifying tourism research that does not include the words tourism or tourist in the title (e.g. 'Host- guest relations in China'). On the other hand it provides an overestimate by counting titles that include the stem 'tour' in the title but are not about tourism (e.g. 'The Ballet Rambert Touring Company'). Visual inspection of the output titles and removal of inappropriate data readily addressed the latter problem. The former problem should not unduly undermine the purposes of this article. It is not the intention to provide an exhaustive summary of RAE tourism research, rather it is to identify its underlying patterns.

\section{FINDINGS AND DISCUSSION}

Research in the RAE was judged by panels operating across 69 Units of Assessment. (A Unit of

Table 3. Examples of smaller research groups

\begin{tabular}{lcccc}
\hline Institution & $\begin{array}{c}\text { Unit of } \\
\text { Assessment }\end{array}$ & Rating & $\begin{array}{c}\text { Number of tourism } \\
\text { researchers submitted }\end{array}$ & $\begin{array}{c}\text { Total number of } \\
\text { tourism } \text { articles }^{\text {a }}\end{array}$ \\
\hline Oxford Brookes & 43 & 2 & 2 & 3 \\
Oxford Brookes & 34 & 4 & 3 & 5 \\
Bristol & 58 & $5^{*}$ & 1 & 1 \\
Bristol & 35 & 4 & 1 & 3 \\
Durham & 37 & 5 & 3 & 3 \\
Durham & 35 & $5^{*}$ & 1 & 3 \\
Durham & 43 & $3 a$ & 1 & 3 \\
Edinburgh & 35 & $5^{*}$ & 1 & 2 \\
Swansea Institute & 34 & 1 & & 1 \\
\hline
\end{tabular}

${ }^{a}$ Note in some cases articles have been removed from published data for reasons of confidentiality. Also some 'new' researchers submitted less than four outputs. 
Assessment is a grouping of subjects and a panel consists of peers who are selected on the basis of their expertise to judge research excellence for a particular UoA). The first issue that needs to be addressed is how well did the RAE accommodate tourism? Although some distinctly minority areas had whole UoAs devoted to their study(e.g. Celtic Studies), tourism did not feature in the title of a single UoA. Beyond the title, however, each panel included an elaborating statement headed 'description and boundaries'. Did tourism appear here? The whole of the document 'Assessment panels' criteria and working methods' (RAE Team, 1999a) was searched for the word 'tourism'. There was just one occurrence (in a document of 148397 words) under UoA 34 (Town and Country Planning).

The lack of a clear home for tourism research under the RAE meant that Universities had to make a choice as to where to place their tourism research. Popular choices were UoA

43 (Business and Management), UoA 69 (Sports-related Subjects), UoA 35 (Geography) and UoA 34 (Town and Country Planning). Some examples of the RAE results are shown in Table 2 (large research groups) and Table 3 (small research groups).

There are a number of observations that may be drawn from the above. The first issue may be termed a structural one. Here the virtual absence of tourism in the UoAs and their detailed descriptions suggests that tourism research is not considered an important, significant or distinct cognate area by those in positions of power in the academic community in the UK. The activities of the tourism academic tribe have not been recognised by the academic elders and chiefs of more established tribes (Becher, 1989). Because of this, like a cuckoo, tourism research has to inhabit alien nests. The second issue is that concerned with outcome. Tourism research was not rated well in comparison with other areas of research. Although there were some individual 5 and $5^{\star}$ contributions, none of the larger research groups scored $5^{\star}$ or 5 , with 4 being the highest level achieved and established groupings such as Bournemouth and North London each rated $3 a$. Third there is a visibility issue. Not only are the activities of the larger research groups obscured by the title of their chosen host UoAs but also there is a further hidden dimension to tourism research with small pockets of work buried in unusual UoAs. These observationseachraisea series of questions and problems for tourism research in the UK for the future and the three key issues-structure, outcome and visibility are now each discussed in turn.

\section{Structure}

The structural issue causes a number of problems. If the current structure of UoAs remains it means that any moves towards a more cohesive tourism field of research will be frustrated. Tourism researchers will be forced to account for the merits of their work not to their immediate peers but to their distant academic cousins in the established disciplines that dominate the UoAs. Unit of Assessment 43 (Business and Management) is the most popular choice for tourism research submissions.

Here it is worth referring to the work of Kuhn (1970) who emphasised the importance of research communities and the paradigms they work within for the construction and development of knowledge. For Kuhn a paradigm represents:

accepted examples of actual scientific practice - from which spring particular coherent traditions of scientific research (1970, p. 10)

Dann (1997) and Tribe (2001) also discuss paradigms especially in the context of tour- ism research and stress that the point about paradigms is that they define the boundaries of accepted methods for research and knowledge creation. Kuhn (1970) looked at knowledge creation at the level of the culture of disciplines (and was interested especially in the progress of scientific knowledge) but his argument can be extended to consider the wider research community and the culture of that community as it relates to the RAE. For it is the dominant UK research community and its culture (i.e. its way of doing things and its accepted and agreed norms) that have supplied 'the paradigm' for the RAE. Kuhn noted that 'research is a strenuous and devoted attempt to force nature into the conceptual boxes supplied by professional education.' 
(1970, p. 5), and that those things 'that will not it into the box are often not seen at all' (1970, p. 24). Although stretching Kuhn's argument somewhat, there is an important point here for tourism re-search, which has had to it into the boxes supplied by those responsible for the construction of the RAE process. These boxes are important because they provide a framework (Bernstein, 1971) that determines what is a relevant contribution to research and what is not. Interestingly, Seaton 1996 and McKercher 2002 discuss the role of 'elders' within the tourism community who act as gatekeepers in the dissemination of tourism knowledge and the steering of research agendas. In the UK under the 2001 RAE, the gates to publicly legitimised tourism knowledge have been overseen by research elders outside the tour- ism community. They have exerted an essentially conservative influence in determining research categories, falling back on traditional, well-established disciplines. In this process, tourism as a discrete and significant area of research, or one that is worthy of measurement in its own right, has been excluded from the overarching paradigm (that supplied by the RAE) that defines legitimate university research in the UK.

The Foucauldian concept of discourse (Foucault, 1971) also provides important insights for an analysis of the structure of the RAE. Foucault describes discourses as ' "regimes of truth" giving as examples medicine, psychiatry, and other forms of disciplinary knowledge' (Usher and Edwards, 1994, p. 85). For Foucault (1974 p. 9) discourses are 'those practices that systematically form the objects of which they peak'. In other words, dis- courses have two significant aspectsthey involve statements and the practices that result from these statements. For example, Foucault demonstrated how the idea of 'madness' cannot be understood as an ahistorical or universal concept, but is constituted by and within psychiatric and medical discourse. This had important implications for the way in which 'madness' was perceived and the way in which those considered 'mad' were treated in practice. Importantly, these discourses, these statements and practices, are not politically neutral but are implicated in relationships of power. In other words it is discourses that define the 'limits of the sayable' (Foucault, 1974). Within discourse, certain statements are sanctioned as 'truth-claims' whereas others are silenced and denied such status. Discourses establish boundaries of inclusivity and exclusivity and this simultaneous sanctioning and denial is an exercise of power. Discursive formations perform an including and excluding function because they provide the rules for what counts as knowledge and what does not, and who speaks with authority and who does not.

Importantly, for Foucault, where there is power, there is also knowledge (Foucault, 1980). Power and knowledge are two sides of the same coin, for those who are invested with the knowledge to make 'truth-claims' also necessarily exercise power. In this context, Foucault conceived power as a relationship that inhabits every sphere of the social world. By thus perceiving power as ubiquitous, Foucault redirected attention from

The grand, overall strategies of power, towards the many, localized circuits, tactics mechanisms and effects through which power circulates-what Foucault calls the 'meticulous rituals' or the 'micro- physics' of power (Hall, 1997, p. 50).

Power at this micropolitical level is not overt but oblique and insidious. It is what Foucault terms a disciplinary kind of power. This kind of power disciplines in the sense that it normalisescertain subjects and objects as 'true' and as valid while it necessarily denies that status to others. So that, following Foucault, relationships of power also inhabit the RAE. It is those who conduct the RAE who are ostensibly invested with the knowledge about what constitutes 'true', quality, research in the UK. Those who conduct the RAE consist of the funding councils responsible for overall strategy, the RAE managers responsible the design and operationalisation of the RAE and the panel members responsible for exercising judgements on research quality. The RAE thus acts as a centre for a disciplinary kind of power, a locus of control at the micropolitical level of the academic research community. On Foucault's view a discourse can perform a repressive role furthering the interests of some groups while suppressing the interests of others. It is within the discourse of the RAE that certain academic fields and disciplines are authorised, are given importance and validity, whereas others are silenced and subjugated. Indeed, within the discourse of the RAE, tourism is subsumed within other academic fields, thus effectively 
obscuring the growing importance and development of tourism as a distinct academic concern. It would appear from the 2001 RAE that it is the discourses of Business and Management and Geography that have gained ascendancy over tourism research (see Table 4). This has vital implications not only for the development of tourism as a separate cognate area, but also for the practice of tourism research. In other words, the discourse of the RAE and specifically its structuring and of UoA panels and choice of experts for peer review will determine the epistemological development and practice of tourism research. In the RAE, Tourism is not able to speak for itself, but is required to speak through the discourses of (e.g.) Business and Management and Geography. We may therefore expect the UK tourism research agenda to be largely constituted by understandings offered by Business and Management and Geography. This will surely strengthen a movement noted by Tribe (1997,p. 654) that 'the business world of tourism is pushing out at the expense of other parts [of tourism]'.

Few panels made any specific reference to tourism in their feedback. However, the Business and Management Panel (UoA 43) made the following specific comments:

The discipline base of tourism has resulted in a relatively mature body of work, with around 20 per cent of international quality. Few centres have critical mass, with output deriving from a small number of experts ranging across the sector. Some work remains of subnational quality, usually due to the relative inexperience of new or young researchers. There is limited evidence of doctoral supervision in the sub-area. Of those submissions in which hospitality or tourism was the sole or predominant discipline, only one centre had a substantial programme. Three tourism/hospitality centres chose to make separate submissions to the panel. But there is no clear evidence from this RAE that the consistent trend to amalgamate hospitality and tourism schools into larger business schools is having either a positive or negative impact on the quality of work (RAE Team, 2002).

Panel 43 seems not to be alert to any substantive issues arising from business school domination of Tourism. Ironically, their lack of attention to Foucauldian or Kuhnian critiques is precisely that predicted by the work of both Foucault and Kuhn. Additionally Panel 43 seems to have overlooked the growth of doctoralsupervision inthearea. For incontrast to the findings of Panel 43, Botterill et al. (in press) found 'a substantive and expanding volume of doctoral studies related to tourism in UK universities'. Indeed they discovered a total of 149 tourism doctoral theses submitted between 1990 and 1999.

The Panel report on UoA 69 (Sports-related subjects) made the following observation:

The Unit of Assessment covers a wide area ranging from sport science to social science research in sport and leisure (including tourism) - Within the sport sciences there exists a clear hierarchy of journals with those at the top having a consistent high quality of articles. In the social science study of sport and leisure, there is as yet not such a clear hierarchy of journals with many journals containing research outputs of inconsistent quality. Researchers are faced with the possibility of publication in specialist journals in the sport, leisure and tourism areas or alter- natively the possibility of publication in mainstream disciplinary journals. At the moment there is a more consistent quality in the latter than the former. The Panel felt that this was a problem for the subject area (RAE Team, 2002).

A clear question mark is held up to the quality of tourism journals in this report. Researchers who heed the advice of Panel members may attempt to relocate the publication of their research out of the tourism journals and into the mainstream disciplinary journals. This may have profound implications for the volume and level of manuscripts sent to tourism journals and the development of tourism as a separate cognate area.

Having considered the implications of RAE structure on tourism research it should also be noted that in a Foucauldian sense power is not totalising or absolute. That is, according to Foucault power also implies resistance and indeed resistance has a dual role vis-a-vis power. On the one 
hand, resistance serves to define and to constitute power and on the other hand, it serves as a potential source for the overthrow of relationships of power. Foucault notes that:

Every power relationship implies, at least in potentia, a strategy for struggle in which the two forces are not superimposed, do not lose their specific nature, or do not finally become confused. Each constitutes for the other a kind of permanent limit, a point of possible reversal. It would not be possible for power relations to exist without points of insubordination which by definition are means of escape - a relationship of confrontation fulfils power and at the same time suspends it (1992, p. 38).

In this sense, we can see that there has been some resistance to the power exercised by the RAE over academic research in the UK. The Sports-related subjects (UoA 69) and Education (UoA 68) Units of Assessment are relative newcomers to the RAE map. They have managed to challenge the traditional academic status quo as evidenced bytheir inclusion in recent RAEs. So it is theoretically possible for tourism academics to challenge the discourse of the RAE, to open it up to alternative interpretations of knowledge, to alternative 'truths' about what constitutes quality in academic research. However, in practice there are less grounds for optimism. The ATHE (Association of Tourism in Higher Education) lobbied strongly in the 2001 RAE consultation period for more visibility for tourism and nominated a tourism expert to sit on a panel. It was unsuccessful on both counts. Moreover, David Botterill (ex-Chair of ATHE) recently wrote:

The creation of a single UoA for tourism studies is unlikely to be a realistic option. However, it might usefully be a manifesto pledge for the ATHE member institutions, in attempting to change the status quo at the funding councils. It may also keep the subject community debate sharply focused upon the structure of future research quality assessment. The result of such action could lead to increased visibility for tourism studies in a revised structure of research quality assessment. A realistic expectation might be that the word 'tourism' appears within one UoA title (Botterill, 2002, p. 73).

\section{Outcomes and visibility}

Under the outcomes heading there are a couple of significant issues. First was tourism given a fair hearing? A key issue here again is lack of it. In many cases submissions had to be placed under UoAs that were not well-placed to judge the work. The problems of different disciplinary traditions and lack of intersubjectivity arise. In extreme cases Lyotard's (1988, p.xi) problem of the 'differend' might obtain ('conflict between at least two parties that cannot be equitably resolved for lack of a rule of judgement applicable to both arguments'). In fact there was not a single tourism expert on any of the panels, although it is known that one business of tourism academic was consulted for UoA 43. The following example demonstrates an example of the problem of lack of it. The University of Luton made its tourism submission under UoA 43. But the description of the team shows a distinct non-business slant to Luton's research: Peter Mason described the Luton team as follows:

I am a geographer, Dr Marcjannna Augustyn has a PhD in economics, Professor Graham Dann taught sociology at the University of the West Indies from the mid-70s to mid-90s, and Professor Tony Seaton has a wealth of media and marketing experience. Along with sociologist Dr Keith Hollinshead and ecologist Dr Andrew Holden, we have a strong, diverse team (University of Luton, 2002, p. 1).

One wonders how the Business and Management Panel judged Dann's 'Writing out the tourist in space and time' or Hollinshead's 'Tourism, hybridity and ambiguity: the relevance of Babha's "third space cultures".

The second outcomes issue is the effects of the ratings. The ratings achieved by tourism research has serious consequences for the future of tourism research. The funding council for England has decided not to fund any research that was rated $3 b$ or less. Research groups rated $3 a$ will be funded for 1 year only and research groups rated 4 will attract very modest funding. 
Indeed the future regime for research funding in tourism looks even more bleak. In the White Paper that sets out a vision for higher education (Department for Education and Skills, 2003) the Government has signalled its intention to make research funding even more highly selective. It is proposing

to identify the very best of the $5^{\star}$ departments which have a critical mass of researchers a $6^{*}$ - and will provide additional resources - over the next three years. At subject as well as at institutional level, it is critical that we focus our resources on the strongest, who bring us the best returns (DES, 2003, p. 30).

This would appear to be particularly harsh on tourism researchers. After all tourism research is a relatively young and developing area. There is surely much existing and emerging talent in $3 \mathrm{~b}$ and 3 a centres and the Government has lost an opportunity to nurture and encourageresearch that is already of, or may well develop into, national or international excellence.

In terms of visibility a number of points arise. First it is rarely possible to separate a tourism score from an overall score. The exception to this is Luton and North London, both of whom submitted discrete groups under UoA 43. Elsewhere, however, tourism sits in with larger groupings. At Strathclyde, for example, a total of 80 researchers were submitted under UoA 43. Of these only nine were identified under Tourism and Hospitality Research and three of these are mainly hospitality. Strathclyde's score fell from 5 in the 1996 RAE to 4 in the 2001 RAE and this must give rise to some interesting post-mortems in trying to identify the researchers responsible for a lower score. At Surrey, 13 out of the 28 researchers submitted in UoA 43 were involved in tourism. In UoA 69 the joint Shefield/Shefield Hallam submission included 24 researchers, of which only eight were speciicallyin tourism. In some cases, e.g. Oxford Brookes, tourism research was sub- mitted to different UoAs (three of a total of 31 submitted to UoA 34 Town and Country Planning, and two of a total of 12 submitted to UoA 43 Business and Management Studies (Hospitality Specialism)). So, apart from Luton and North London we do not have very precise information about the ratings of tourism research.

Second there are pockets of tourism research that are hidden in odd corners. In fact the search of the RAE submission reveals that the term 'tourist/ism' was present in the title of a research output in no less than 92 higher education institutions in the UK. In some cases this research is part of top-rated submissions. Examples of this are Cloke and Perkins (1998), part of Bristol's 5* rated UoA 58 (Archaeology) submission; Crang (1997), part of Durham's 5* Geography submission; and Hughes $(1996,1998)$ and Hughes and Leslie (1997), part of Edinburgh's $5^{*}$ Geography submission. Additionally tourism was evident in the $5^{*}$ Sociology submissions from Exeter, Manchester and Lancaster, Salford's $5^{*}$ Built Environment submission and University College, London's $5^{\star}$ geography submission.

Table 4 gives a fascinating picture of the way in which tourism research has been atomized by the RAE, and at the same time illustrates how far it has permeated across the range of UoAs. There is a tourism-related output in 31 out of the total of 69 UoAs. From the table it can also be seen that Business and Management, Geography, Art and Design, Sociology and Sports-related Subjects were the most significant UoAs for the submission of tourism research. What the table also hints at is the considerable impact and presence that UK tourism research might have had were it to have been given its own UoA.

\section{CONCLUSION}

The overall conclusion of this discussion is that it makes sense to talk about the RAE-ification of tourism research in the UK in order to draw attention to some of the significant hidden effects of the RAE. The discourse of the RAE has exerted a disciplinary kind of power over academic research in the UK and has had significant effects on tourism research in particular. First it has transformed and will continue to transform the research agenda by the imposition of its rigid and inappropriate structures, which are largely insensitive to the particular needs of tourism. In other words structure here is determining the research agenda. Second, it has neither rated tourism research highly nor has it offered tourism research funding commensurate with 
Table 4. Tourism research outputs under Unit of Assessment (UoA) titles

\begin{tabular}{|c|c|c|}
\hline UoA & Title & frequency \\
\hline 43 & $\begin{array}{l}\text { Business and Management } \\
\text { Studies }\end{array}$ & 3 \\
\hline 35 & Geography & 26 \\
\hline 64 & Art and Design & 12 \\
\hline 42 & Sociology & 8 \\
\hline 69 & Sports-related Subjects & 7 \\
\hline 37 & Anthropology6 & \\
\hline 34 & Town and Country Planning & 4 \\
\hline 68 & Education & 4 \\
\hline 58 & Archaeology & 4 \\
\hline 33 & Built Environment & 4 \\
\hline 50 & $\begin{array}{l}\text { English Language and } \\
\text { Literature }\end{array}$ & 3 \\
\hline 65 & $\begin{array}{l}\text { Communication, Cultural and } \\
\text { Media Studies }\end{array}$ & 3 \\
\hline 60 & $\begin{array}{l}\text { History of Arts, Architecture } \\
\text { and Design }\end{array}$ & 3 \\
\hline 25 & Computer Science & 3 \\
\hline 39 & Politics and International & 3 \\
\hline 40 & $\begin{array}{l}\text { Studies } \\
\text { Social Policy and } \\
\text { Administration }\end{array}$ & 2 \\
\hline 45 & American Studies & 2 \\
\hline 66 & $\begin{array}{l}\text { Drama, Dance and Performing } \\
\text { Arts }\end{array}$ & 2 \\
\hline 47 & Asian Studies & 2 \\
\hline 2 & $\begin{array}{l}\text { Community-based Clinical } \\
\text { Subjects }\end{array}$ & 2 \\
\hline 59 & History & 2 \\
\hline 15 & Agriculture & 2 \\
\hline 21 & Environmental Sciences & 1 \\
\hline 11 & $\begin{array}{l}\text { Other Studies and Professions } \\
\text { Allied to Medicine }\end{array}$ & 1 \\
\hline 30 & $\begin{array}{l}\text { Mechanical, Aeronautical and } \\
\text { Manufacturing }\end{array}$ & 1 \\
\hline 38 & Economics and Econometrics & 1 \\
\hline 67 & Music & 1 \\
\hline 51 & French & 1 \\
\hline 48 & European Studies & 1 \\
\hline 36 & Law & 1 \\
\hline 61 & $\begin{array}{l}\text { Library and Information } \\
\text { Management }\end{array}$ & 1 \\
\hline
\end{tabular}

\footnotetext{
${ }^{\text {a }}$ Frequencies of institutional submissions to Units of Assessment with the term tourism or tourist in the title of at least one output.
} 
its extraordinary economic, social and cultural significance. It has offered tourism research no compensation for its youthfulness nor has it offered any significant role to tourism re-searchers in the RAE process.

Third it has made tourism research much less visible than it deserves. In short tourism research has not been legitimised by the wider UK academic community. So although authors such as Dann and Phillips (2001) have suggested that tourism research is moving away from pure quantification and towards a more qualitative approach, this paper suggests that the RAE structure may restrict moves towards a more open tourism research agenda. It may serve to perpetuate the concern voiced by Meethan (2002) that research in tourism is uncritical and failing to evaluate the effects of tourism in societies because it seems likely that UoA 43 will continue to exert a significant Business and Management influence on tourism research into the future.

Finally, it is noted that a favorite theme amongst tourism researchers is the meaning and consequences of peripherality (Blomgren and Sorensen, 1998). Ironically tourism research finds itself enmeshed with significant issues of power/knowledge, position, hegemony and emasculation resulting from its relegation to the periphery of an RAE dis- course in the UK. Similarly, it faces all the problems of those inhabiting peripheral spaces in changing things. Readers of Kuhn (1970) will recall the ways in which existing paradigms resist change and will find few grounds for optimism that the next RAE will be more accommodating or encouraging for tourism research. Yet, readers of Foucault should bear in mind the concept that where there is power there is also resistance. The question is, to what extent are tourism academics able to resist the disciplinary power of the discourse of the RAE?

\section{ACKNOWLEDGMENTS}

The author would like to thank Donna Chambers for her insightful comments on an earlier draft of this paper. 


\section{REFERENCES}

Becher T. 1989. Academic Tribes and Territories. Open University Press: Buckingham.

Bernstein B. 1971. Classification and framing. In Knowledge and Control, Young M (ed.). Collier MacMillan: London.

Blomgren K, Sorensen A. 1998. Peripherality- factor or feature? Reflections on peripherality in tourism research. Progress in Tourism and Hospitality Research 4(4):319-336.

Botterill D. 2002. Tourism studies and research quality assessment in UK universities. Journal of Hospitality, Leisure, Sport and Tourism Education 1(2): 71-74.

Botterill D, Haven C, Gale T. In press. A survey of doctoral theses accepted by universities in the UK and Ireland for studies related to tourism, 1990-1999. Tourist Studies.

Cloke P, Perkins H. 1998. 'Cracking the canyon with the awesome foursome': representation of ad- venture tourism in New Zealand. Environment and Planning D: Society and Space 16:185-218.

Crang M. 1997. Picturing practices: research through the tourism gaze. Progress in Human Geography 21: 359373.

Dann G. 1997. Paradigms in tourism research. Annals of Tourism Research 24: 472-474.

Dann G, Phillips J. 2001. Qualitative tourism research in the late twentieth century and beyond. In Tourism in the Twenty first Century: Reflections on Experience, Faulkner B, Moscardo G, Laws E (eds). Continuum: London; 247-265.

DES. 2003. The Future of Higher Education. Department of Education and Skills, HMSO: Norwich.

Foucault M. 1971. L'ordre du Discours. Gallimard: Paris.

Foucault M. 1974. The Archaeology of Knowledge. Tavistock: London.

Foucault M. 1980. Power/Knowledge; Selected Inter- views and Other Writings 1972-77. Harvester Press: Brighton.

Foucault M. 1992. The subject and power. In Critical Theory: the Essential Readings, Ingram D, Simon- Ingram $\mathrm{J}$ (eds). Paragon House: New York; 303- 319.

Hall S (ed.). 1997. Representation: Cultural Representations and Signifying Practices. Sage/The Open University: London.

Hughes C. 1996. Threshold, carrying capacity and the sustainability of tourism. A case study of Belize. Caribbean Geography 7(1):36-51.

Hughes C. 1998. Tourism and the semiological realisation of space. In Destinations: Cultural Landscapes of Tourism, Ringer G (ed.). Routledge: London; 17-32.

Hughes C, Leslie D. 1997. Agenda 21, local authorities and tourism in the UK. Managing Leisure 2(3):143154.

Kuhn TS. 1970. The Structure of Scientific Revolutions, 2nd edn. University of Chicago Press: Chicago, IL.

Lyotard J (translated by G. Van den Abeele). 1988. The Differend: Phases in Dispute. University of Minneapolis

Press: Minneapolis, MN.

McKercher B. 2002. The privileges and responsibilities of being a referee. Annals of Tourism Research 29(3): 856-859.

Meethan K. 2002. Tourism in a Global Society: Place, Culture, Consumption. Palgrave: Basingstoke.

RAE Team. 1999a. Research Assessment Exercise 200l: Assessment Panels' Criteria and Working Methods (RAE Circular 5/99). RAE Team: Bristol.

RAE Team. 1999b. Guidance on Submissions (RAE Circular 2/99). RAE Team: Bristol.

RAE Team. 2002. RAE 2001-Overview Reports from the Panels. RAE Team: Bristol.

Seaton A. 1996. Blowing the whistle on tourism referees. Tourism Management 17:397-399.

Tribe J. 1997. The indiscipline of tourism. Annals of Tourism Research 24(3).

Tribe J. 2001. Research paradigms and the tourism curriculum. Journal of Travel Research 39: 442-448.

University of Luton. 2002. Press Release (14.01.2002). University of Luton: Luton.

Usher R, Edwards R. 1994. Postmodernism and Education. Routledge: London. 